\title{
Padrões recentes de inserção e mobilidade no trabalho doméstico no Brasil metropolitano: descontinuidades e persistências
}

\author{
Larissa Giardini Simões \\ Ana Maria Hermeto**
}

\begin{abstract}
Essencialmente feminino, negro e pobre, o emprego doméstico é tratado diferentemente até mesmo pela legislação. Esse artigo tem o objetivo de identificar como o ciclo de vida, geração e outras características individuais da mulher, assim como fatores conjunturais, afetam a chance de estar e permanecer no emprego doméstico remunerado, no Brasil metropolitano em anos recentes. Dados da Pesquisa Mensal do Emprego, de 2002 a 2015, foram utilizados em uma modelagem log-linear de idade, período e coorte das frequências de transição e imobilidade de categorias de ocupação. A conjuntura tem o maior efeito, seguido de coorte. Essa é uma ocupação que está encolhendo e "envelhecendo": menos jovens estão se tornando domésticas enquanto mulheres mais velhas ocupam cada vez mais espaço, combinando o adiamento da saída do mercado de trabalho com a menor mobilidade ocupacional em uma fase mais avançada da vida. Além disso, existe uma grande influência em ser negra na inserção/mobilidade ocupacional que está mudando entre as coortes. Entretanto, a diferença na probabilidade entre brancas e negras de trabalharem como domésticas permanece constante. Ainda, o emprego doméstico possui maior mobilidade do que os demais, indo contra a noção prévia de "armadilha da ocupação", sendo a aparente mobilidade devida às características individuais das trabalhadoras.
\end{abstract}

Palavras-chave: Emprego doméstico. Mobilidade ocupacional. Envelhecimento. Ciclo de vida.

\footnotetext{
* Centro de Desenvolvimento e Planejamento Regional (Cedeplar), Universidade Federal de Minas Gerais (UFMG), Belo Horizonte-MG, Brasil (larissagiardini@gmail.com; https://orcid.org./0000-0003-3541-3975).

** Centro de Desenvolvimento e Planejamento Regional (Cedeplar), Universidade Federal de Minas Gerais (UFMG), Belo Horizonte-MG, Brasil (ahermeto@cedeplar.ufmg.com; https://orcid.org./0000-0001-8331-1928).
} 


\section{Introdução}

A importância dos trabalhadores domésticos vai desde o grande número de pessoas exercendo essa profissão (em 2018 o trabalho doméstico representou 6,8\% dos empregos no Brasil, segundo o IBGE), até a função de cuidado e o lugar estratégico que ocupa na vida dos indivíduos. Assim, a manutenção da invisibilidade dessa ocupação é preocupante, principalmente levando em conta seu papel na perpetuação da segregação racial e na manutenção da divisão sexual do trabalho.

Existe um perfil específico de trabalhadoras: essencialmente feminino, negro e pobre. Diferentemente dos homens, que são destinados à esfera produtiva, o papel de cuidado é delegado historicamente à mulher, cujo lugar é o domicílio e a esfera reprodutiva (KERGOAT, 2003). Ainda, é fundamental para a compreensão da lógica dessa ocupação ter clara a interseção entre os aspectos de gênero e raça, já que as domésticas são em sua maioria mulheres negras. A presença maciça de negros no serviço doméstico remunerado deriva do contexto brasileiro de escravidão, em que a ideia do trabalho manual como inferior é reforçada e atrelada a ideologias racistas e assimetrias de oportunidades (BYELOVA, 2014).

0 trabalho doméstico remunerado é uma ocupação com características próprias, já que não participa do circuito da produção de bens e serviços, mas sim da reprodução da força de trabalho. Esse trabalho, quando realizado pela própria dona de casa, é visto em contraste com trabalho (DUFFY, 2007) e, quando realizado por uma mulher contratada, não possui o mesmo status de trabalho do que aqueles realizados fora do domicílio, em atividades produtivas. Maneschy (2013, p. 209) argumenta que "as atividades domésticas não são, em princípio, trabalho, muito menos profissão, embora cruciais na reprodução social das famílias, das comunidades locais e, por extensão, do próprio sistema econômico capitalista".

As trabalhadoras não têm acesso umas às outras para criar uma identidade de classe, já que o trabalho é realizado dentro dos domicílios, também gerando um falso senso de pertencimento à família (OLIVEIRA; COSTA, 2012) que dificulta a profissionalização. Até mesmo na legislação brasileira essa ocupação foi tratada com excepcionalidades desde o seu reconhecimento como profissão, que só se deu em 1972. Na Constituição de 1988, direitos conquistados pelo conjunto de trabalhadores urbanos foram excluídos a essas trabalhadoras. A Emenda Constitucional 72, conhecida como PEC das domésticas, aprovada em 2013, representou uma mudança nesse quadro de assimetria, ao estender a essas profissionais alguns dos direitos que não eram até então atribuídos a elas. Apesar da importância que essa mudança representou, grande parte das domésticas ainda segue desprotegida e sem acesso aos "novos" direitos conquistados (PINHEIRO; FONTOURA; PEDROSA, 2011).

Os papéis ocupacionais localizam o indivíduo no espaço social, preparando o cenário para a interação com outra pessoa, já que as pessoas compartilham visões sobre ocupações, como a habilidade necessária, a intensidade de demanda física e, mais especificamente, 
quanto é o prestígio de cada ocupação (TREIMAN, 1977). Teria então o trabalho doméstico o mesmo prestígio ocupacional que outras ocupações com rendimentos e requerimentos de habilidades semelhantes? Ou as características específicas dessa ocupação impõem aos trabalhadores processos diferentes daqueles presentes em outras atividades? A existência de imobilidade ocupacional na ocupação, com a escolha de inserção como empregado doméstico acarretando a chamada armadilha da ocupação (SAITO; SOUZA, 2008), pode ser uma das evidências que apontam para um processo de segregação.

Apesar dessa ampliação dos direitos, a proporção de mulheres brasileiras no trabalho doméstico remunerado tem diminuído nos últimos anos, acompanhada por um envelhecimento das domésticas. Essa mudança não acontece da mesma forma para as mulheres negras e brancas, já que o envelhecimento ocorreu antes para o segundo grupo (PINHEIRO; FONTOURA; PEDROSA, 2011). 0 envelhecimento dessa ocupação pode ser reflexo apenas da maior longevidade da população em geral, levando a um adiamento das aposentadorias. Por outro lado, esse aumento geral na expectativa de vida causaria também um crescimento na procura por esse serviço, mais especificamente para o cuidado de idosos. Movimentos de aquecimento e retração da economia também afetam a demanda por esse trabalhador, já que influenciam o poder aquisitivo das famílias, demandantes desse serviço, e mudam a oferta de trabalho ao alterar a disponibilidade de empregos em ocupações alternativas. Esses são apenas alguns dos determinantes capazes de influenciar o comportamento dos trabalhadores nesse mercado de trabalho, que, além de possuir características únicas, apresenta várias dimensões essenciais para sua compreensão.

Esse artigo pretende investigar a escolha ocupacional das domésticas de uma maneira dinâmica, verificando a existência de padrões específicos de inserção e mobilidade no trabalho doméstico, distintos de outros tipos de trabalho, principalmente outras ocupações manuais. Existiriam evidências da "armadilha da ocupação", que representaria uma maior imobilidade nessa ocupação do que nas demais? Investiga-se também a influência de mudanças institucionais, geracionais e do ciclo de vida individual nesse processo de transformação. Ainda referente ao padrão de mobilidade envolvendo domésticas, qual éa influência de outras características das trabalhadoras, como raça, escolaridade e posição no domicílio, nesse processo?

De acordo com esses objetivos, são utilizados dados da Pesquisa Mensal do Emprego de 2002 a 2015, realizada pelo IBGE, sobre mulheres ${ }^{1}$ de 15 a 71 anos de idade, para a construção de matrizes com as frequências das transições da condição de trabalho e ocupação no intervalo de um ano. A estratégia estatística é, por meio de modelos que decompõem as mudanças em efeitos de idade, período e coorte (IPC), identificar a influência destas na inserção das mulheres no mercado de trabalho do serviço doméstico remunerado. Adicionalmente, outras características da mulher podem influenciar sua colocação

\footnotetext{
${ }^{1}$ São consideradas as mulheres residentes da área urbana de seis regiões metropolitanas: São Paulo, Rio de Janeiro, Belo Horizonte, Porto Alegre, Salvador e Recife. Os homens, por representarem uma parcela muito pequena dos trabalhadores dessa ocupação (DIEESE, 2013), não foram incluídos na amostra.
} 
ocupacional, como cor/raça, escolaridade, região metropolitana e condição da mulher no domicílio. Diversos modelos log-lineares são estimados para medir e comparar a influência de cada característica na distribuição das mulheres entre as condições de origem e destino.

A seguir é feita uma revisão dos principais fatores que influenciam a inserção e transições ocupacionais. Posteriormente, abordam-se a base de dados utilizada e os aspectos metodológicos. São discutidos os principais resultados encontrados e levantadas algumas discussões e, por fim, apresentam-se as conclusões do trabalho.

\section{Transições ocupacionais e seus determinantes}

Para compreender os padrões específicos que se formam no mercado de trabalho das domésticas, são necessários conceitos e modelos que compreendam a inserção e transição de trabalhadores em determinadas ocupações de maneira geral. Assim, é importante identificar quais são os principais fatores que influenciam as transições ocupacionais realizadas pelas mulheres envolvidas no trabalho doméstico remunerado captadas pelos dados longitudinais.

A idade está associada positivamente à inclusão no mercado de trabalho, seja por motivos como a maturidade psicológica, ou acumulação de recursos ligados ao trabalho e de capital humano (PHANG, 1995). Essa relação positiva acontece até que o indivíduo alcance uma certa idade, quando iniciam-se os movimentos de saída do mercado de trabalho para a aposentadoria. 0 salário reserva também deve aumentar com a idade, uma vez que há acumulação de renda proveniente do trabalho ou aposentadoria. Entretanto, esse aumento é mais significativo para trabalhadores mais qualificados, que já possuem salários reserva maiores desde o começo do ciclo de vida (REIS; GONZAGA, 2006). Mais especificamente para as mulheres, a idade é um indicador do estágio de vida, em relação tanto ao status marital e presença de filhos quanto à situação no mercado de trabalho. A posição na família à qual a mulher pertence também influencia diretamente sua decisão de participar ou não do mercado de trabalho (PHANG, 1995).

Além disso, indivíduos procuram pelo emprego que melhor se enquadra em suas preferências e suas habilidades percebidas, em circunstâncias que incluem informação incompleta das oportunidades de trabalho e alto custo de procura de trabalho. Uma correspondência ruim entre emprego e habilidade (mismatch) é mais provável de ocorrer quando os indivíduos são mais jovens e inexperientes, acarretando maiores taxas de mobilidade ocupacional e de emprego entre os mais jovens (DEX; BUKODI, 2013).

Outra relação entre a mobilidade e a idade decorre do fato de o capital humano desenvolvido pelos trabalhadores ser, em parte, específico para a ocupação que desempenham e, assim, à medida que se ganha mais experiência em uma ocupação, essa habilidade específica torna maior o custo da mudança para outra ocupação (AUTOR; DORN, 2009). Dessa forma, o sacrifício da mobilidade ocupacional é maior em indivíduos mais velhos, 
especialmente para trabalhadores mais qualificados, que possuem um maior capital humano específico (REIS; GONZAGA, 2006).

À medida que há um declínio em uma ocupação, seja por avanços tecnológicos que tornem essa ocupação obsoleta ou por mudanças sociais e institucionais que alterem a oferta desse trabalho, os trabalhadores mais velhos terão menos incentivo para abandoná-la, ao mesmo tempo que os mais jovens não terão incentivo para integrá-la. Assim, uma ocupação envelhecerá à medida que se reduz em número de trabalhadores e que a média de idade dos trabalhadores aumenta.

Aspectos conjunturais também são importantes em análises das transições ocupacionais, pois constituem os efeitos de período, que são eventos ou mudanças ambientais que afetam indivíduos de todas as coortes e todas as idades simultaneamente. No caso do trabalho doméstico remunerado, o período como dimensão de análise é especialmente importante, uma vez que a ocupação passou por algumas mudanças na legislação que podem ser determinantes para alterações nos padrões de contratação e oferta desse trabalho.

Considerando o comportamento do empregador, ou seja, da demanda pela mão de obra, percebe-se que patamar de exigência na contração varia à medida que as condições de mercado flutuam, levando a um ajustamento de qualidade da força de trabalho. Dessa forma, quando não há muitos desocupados, os patrões reduzem seus requerimentos de "habilidade" para suas vagas e, do mesmo modo, aumentam os níveis de exigência quando enfrentam um mercado de trabalho com excesso de oferta. Esse processo de variação do nível médio de habilidade de cada ocupação representa um movimento contracíclico (DEX; BUKODI, 2013), relacionando as características econômicas do período e a mobilidade ocupacional.

Os ciclos econômicos influenciam não só a demanda pelo trabalho, mas também a procura por emprego. Em uma situação de depressão, o custo de procurar uma nova posição aumenta à medida que provavelmente se levará mais tempo para encontrar um emprego que atenda às expectativas do indivíduo. Assim, os benefícios potenciais de procurar outro emprego diminuem e os indivíduos estão mais propensos a aceitarem mais combinações ruins entre aspirações e vagas. As pessoas se preocupam mais em manter o emprego e menos em obter o emprego "perfeito" em situações de economia desaquecida, resultando menos transições voluntárias (DEX; BUKODI, 2013). O salário reserva também sofre influência de alterações no ambiente macroeconômico e trabalhadores menos qualificados têm menor capacidade de proteção dos seus ativos e remunerações contra a inflação, já que há maior dificuldade de indexação dos salários e acesso ao mercado financeiro (REIS; GONZAGA, 2006).

O terceiro componente principal de análise é a coorte, que consiste no pertencimento a um grupo de indivíduos que apresentaram o mesmo evento de vida em dado período do tempo; nesse caso o evento considerado é o nascimento. Diferenças persistentes entre as coortes são originadas nas experiências únicas compartilhadas pelos indivíduos, além de reações específicas de pessoas com diferentes idades ao mesmo acontecimento e 
contexto histórico. Diferenças educacionais entre coortes podem surgir da variação entre a "quantidade" estudada e a qualidade do ensino que foi ofertado a esses indivíduos (HERMETO, 2002). 0 conceito de coorte é crucial no estudo das mudanças sociais, pois nesses processos cada nova coorte é um possível intermediário que, apesar de não causar a mudança, permite que ela aconteça ao ser um veículo de introdução de novas posturas e valores (RYDER, 1965).

As características do mercado de trabalho no momento de entrada da coorte nesse mercado já fazem parte da construção da experiência específica de um grupo de indivíduos. A estrutura ocupacional da coorte não está cristalizada na entrada no mercado de trabalho, mas a configuração imposta por essa em cada história econômica individual cria uma forte dependência ao longo da vida. Além disso, a trajetória ocupacional de uma coorte é influenciada pela presença de paz ou guerra, depressão ou crescimento em cada estágio de sua carreira (RYDER, 1965). No caso das domésticas, esse efeito é especialmente importante, pois há no período recente uma tendência de mais escolarização das sucessivas coortes e um período de crescimento econômico mais prolongado, caracterizado pela desconcentração de renda e pelo aumento da oferta de empregos menos vulneráveis e mais valorizados, exercendo grande impacto na trajetória das trabalhadoras de novas gerações, cuja inserção laboral coincidiu com essa conjunção de fatores (GUERRA, 2017).

Assim, idade, período e coorte são elementos de análise fundamentais para a compreensão das transições ocupacionais das empregas domésticas, mas outros elementos de análise podem refletir na escolha das mulheres em relação ao mercado de trabalho doméstico. Raça, por exemplo, deve ser incluída, já que existe um padrão racial entre as domésticas, no Brasil, que são em sua grande maioria negras (PINHEIRO; FONTOURA; PEDROSA, 2011). Por outro lado, características regionais podem influenciar tanto a capacidade de alocação dessas trabalhadoras, ou seja, a oferta considerando ocupações alternativas, como a demanda levando em conta o poder aquisitivo das famílias empregadoras.

É importante considerar também a condição que a mulher ocupa na sua estrutura familiar, uma vez que as responsabilidades e obrigações de mulheres chefes de família não são as mesmas de mulheres cônjuges e diferem, ainda, de mulheres que ocupam a posição de filha no domicílio. Mulheres chefes de família têm salários reserva diferentes e possuem menos condições de suportar o ônus do desemprego que uma busca por melhor emprego ocasiona. Além dessas, a escolaridade como formadora do capital humano permite maior amplitude de escolha à mulher e é uma variável fundamental na compreensão do processo de inserção ocupacional e de transição entre ocupações (PHANG, 1995). 


\section{Metodologia e fonte de dados}

\section{Modelos log-lineares para a estimação da mobilidade}

Considerando o objetivo desse estudo, que é investigar a existência de padrões específicos de inserção e mobilidade no trabalho doméstico, a estratégia utilizada é a construção de matrizes de transição da condição de trabalho dos indivíduos, relacionando as categorias iniciais e finais em um intervalo de 12 meses. Para analisar as transições relacionadas ao mercado de trabalho doméstico, é necessário que todas as demais condições sejam incluídas nas matrizes para separar as tendências gerais do mercado de trabalho e as mudanças ocupacionais intrínsecas a essa ocupação

Modelos log-lineares possibilitam a obtenção de medidas isentas da influência das distribuições marginais, já que são utilizadas as taxas relativas, obtidas em termos de razão de chances ou odds ratio. Modelos log-lineares generalizados são extensões que permitem que a média da população dependa de um preditor linear, por meio de uma função de ligação não linear, e que a distribuição de probabilidade da variável resposta seja membro de uma família exponencial de distribuição. No caso, é estimado um modelo de contagem com função de ligação logarítmica e distribuição de Poisson.

Nesse sentido, o modelo que contempla os efeitos isolados de cada variável e efeito interação é chamado saturado. Ele reproduz exatamente a tabela original, na medida que não há diferenças entre as frequências esperadas e as observadas. 0 número de parâmetros independentes estimados no modelo é o número de células nas tabelas cruzadas de contingência. Caso esses valores sejam diferentes, o modelo é insaturado. Esse é o modelo log-linear, apresentado na forma aditiva:

$\ln F_{i j}=\mu+\lambda_{i}^{O}+\lambda_{j}^{D}+\lambda_{i j}^{O D}$

Nesse caso, $\mu=\ln \eta ; \lambda_{i}^{O}=\ln \tau_{i}^{O} ; \lambda_{j}^{D}=\ln \tau_{j}^{D}$ e $\lambda_{i j}^{O D}=\ln \tau_{i j}^{O D}$. Valores de $\lambda$ iguais a zero indicam que não há efeito da variável na alocação das frequências entre as categorias. As demais variáveis são incluídas no modelo da mesma forma, incorporando-se efeitos puros das variáveis e ainda efeitos de interação entre essas. 0 modelo mais simples que pode ser estimado inclui apenas o fator de escala, $\mu$ ou $\eta$ e é chamado modelo nulo. 0 modelo de independência considera apenas os efeitos puros das variáveis e é obtido retirando-se os efeitos de interação do modelo saturado.

Os modelos do tipo log-linear topológicos permitem que se atribuam chances similares de mobilidade ou imobilidade a determinados grupos de células, já retirando o efeito das distribuições marginais distintas de cada classificação incluída no modelo (FEATHERMAN; HAUSER, 1976). Matrizes agrupam categorias distintas de ocupação e descrevem como algumas categorias se assemelham nos padrões de mobilidade e, da mesma forma, como os grupos se distinguem. Hipóteses são levantadas incluindo apenas os grupos de origem e destino ocupacionais e não incluem as demais dimensões analisadas no modelo, como idade, período e coorte. 0 Quadro 1 apresenta as hipóteses testadas utilizando os modelos topológicos. 
QUADRO 1

Hipóteses testadas nos modelos topológicos

\begin{tabular}{|lll|}
\hline Hipóteses & Justificativa \\
\hline 1 & $\begin{array}{l}\text { Independência (indiferença } \\
\text { entre origens e destinos) }\end{array}$ & $\begin{array}{l}\text { Não existem fatores que atraiam de maneira diferente os indivíduos para } \\
\text { as diferentes categorias }\end{array}$ \\
\hline 2 & $\begin{array}{l}\text { Imobilidade e mobilidade } \\
\text { Quem sai da sua posição inicial tem a mesma probabilidade de se dirigir a } \\
\text { qualquer outro estado, independente da “distância” }\end{array}$ & $\begin{array}{l}\text { Existe uma ordenação hierárquica entre as classes apresentadas e, assim, } \\
\text { a mobilidade ascendente difere da descendente }\end{array}$ \\
\hline 3 & $\begin{array}{l}\text { Mobilidade acima e abaixo } \\
\text { da diagonalções consideram a } \\
\text { "distância” }\end{array}$ & $\begin{array}{l}\text { Existe uma ordenação hierárquica entre as categorias e, assim, há } \\
\text { diferentes “distâncias” entre as transições }\end{array}$ \\
\hline 5 & $\begin{array}{l}\text { Transições envolvendo } \\
\text { inatividade e desemprego }\end{array}$ & $\begin{array}{l}\text { Movimentos envolvendo desocupação e inatividade apresentam padrão } \\
\text { distinto em relação aos movimentos entre grupos de ocupações }\end{array}$ \\
\hline 6 & $\begin{array}{l}\text { Imobilidades } \\
\text { Incentivos para permanecer em cada categoria são distintos dependendo } \\
\text { da categoria ocupada }\end{array}$ \\
\hline 7 & Inatividade e desocupação & \begin{tabular}{l} 
Existe desemprego oculto pelo desalento \\
\hline
\end{tabular}
\end{tabular}

Fonte: Elaboração das autoras.

Vários modelos podem ser obtidos, incluindo diferentes matrizes de peso, variáveis e ainda incluindo interação. Comparação das estatísticas que avaliam a qualidade do ajustamento, como a razão de verossimilhança $\left(\mathrm{G}^{2}\right)$ ajustada pelos graus de liberdade (g.l), o critério de informação bayesiano (BIC) e o critério de informação de Akaike (AIC), auxilia a escolha da melhor estrutura de mobilidade (POWERS; XIE, 2008).

\section{Modelo idade, período e coorte (IPC)}

Decompor as mudanças nas categorias criadas em componentes de idade, período e coorte permite analisar as transições ocupacionais de cada indivíduo da amostra, tendo em vista as suas características demográficas, além das condições econômicas que ambientaram os eventos em questão. Esse método é utilizado na análise de dados longitudinais obtidos de repetidas pesquisas cross-section; as transições analisadas são as efetivamente realizadas por indivíduo da amostra, mas não se acompanha o mesmo indivíduo ao longo de todo o período.

Dessa forma, são construídos 19 grupos etários (I) trienais e cinco grupos de períodos (P) (2002, 2005, 2008, 2011 e 2014) e, nessa categorização, estão implícitas as coortes (C), que representam o corte cronológico ao nascer. Os intervalos iguais (trienais) são um requisito para a formulação do modelo e os 19 grupos etários analisados em cinco períodos geram 23 coortes distintas

Assim, como "período = coorte + idade", existe um problema de identificação, sendo possível isolar apenas dois dos três efeitos. Várias formas de se contornar esse problema já foram propostas (YANG; FU; LAND, 2004) e a estratégia utilizada é a imposição de restrições lineares entre os coeficientes para identificar o modelo. A restrição utilizada é a de igualdade entre os coeficientes das últimas coortes, já que se supõe que os efeitos de coorte sejam menores à medida que os indivíduos fiquem mais velhos. Ainda se admite que não há tempo para grandes mudanças sociais entre coortes consecutivas. 
Uma sequência de modelos log-lineares é estimada: modelo nulo, sem variáveis explicativas; modelos de efeitos brutos de idade, período e coorte, ou seja, que incluem apenas uma dessas dimensões; modelos de efeitos combinados dois a dois; e, por fim, um modelo incluindo os três fatores simultaneamente. Esses modelos são combinados também com as demais variáveis e com as matrizes que atribuem chances diferentes de mobilidade aos grupos.

\section{A Pesquisa Mensal do Emprego}

São utilizados dados da Pesquisa Mensal do Emprego (PME) entre 2002, quando foi adotada nova metodologia, e 2016, ano de seu encerramento. ${ }^{2}$ Restringida à área urbana de seis regiões metropolitanas do Brasil (Recife, Salvador, Belo Horizonte, Rio de Janeiro, São Paulo e Porto Alegre), a PME forma um painel rotativo em que cada unidade domiciliar selecionada é pesquisada por quatro meses consecutivos, permanece oito meses sem ser pesquisada e é pesquisada por mais quatro meses antes de ser excluída da amostra. Trata-se de uma fonte de dados adequada, pois apresenta informações sobre inserção, permanência ou transição dos trabalhadores.

Da PME são extraídas as variáveis idade, ${ }^{3}$ referente à primeira entrevista, período, que é o ano relativo à primeira entrevista, e a partir dessas duas extrai-se a coorte, intervalo do nascimento do indivíduo. Além dessas, são utilizadas da pesquisa outras variáveis individuais, como a região de residência e a condição no domicílio, ou seja, se o respondente é o principal responsável pelo domicílio, cônjuge, filho ou outros (outro parente, agregado, pensionista, etc.). A variável cor/raça é baseada na autodeclaração do indivíduo e foi agrupada em duas categorias: negros e brancos, sendo que os demais indivíduos foram excluídos da amostra. A variável educação foi construída de acordo com o nível de escolaridade mais alto alcançado: superior, ensino médio, ensino fundamental II, ensino fundamental I e alfabetização.

Por fim, a categorização da ocupação foi desenvolvida de acordo com a ocupação declarada pelo indivíduo nas duas entrevistas analisadas. ${ }^{4} \mathrm{~A}$ princípio, as mulheres foram divididas em três grupos: ocupadas, desocupadas e inativas, sendo que os dois primeiros formam a população economicamente ativa. Como é importante, ainda, considerar transições entre inativas e domésticas e vice-versa, as mulheres que não estavam economicamente ativas também foram incluídas na amostra. Dentro do grupo de ocupadas, subdivisões além de domésticas foram criadas para identificar qual caminho e qual origem

\footnotetext{
${ }^{2}$ As bases PNAD e PME foram substituídas pela PNAD Contínua.

${ }^{3}$ Foram consideradas mulheres com até 71 anos de idade, de acordo com o intervalo trienal necessário para o modelo IPC, e por considerar que esse seja o intervalo crítico de participação no mercado de trabalho.

${ }^{4}$ A localização do indivíduo no painel da PME foi realizada a partir do algoritmo desenvolvido por Ribas e Soares (2008), que utiliza características individuais para identificar a mesma pessoa ao longo das entrevistas.
} 
as mulheres envolvidas nesse mercado de trabalho estão tomando: ${ }^{5}$ trabalhos manuais, intermediários e superiores.

\section{Resultados}

Os modelos log-lineares permitem analisar quais efeitos são predominantes na dinâmica do trabalho doméstico, já que conseguem isolar o efeito singular de cada fator contribuinte. Segundo os ajustes dos modelos log-lineares de transição envolvendo apenas idade, período e coorte, além das categorias origem e destino, a dimensão coorte (modelo 12) apresenta o maior poder preditivo das transições ocupacionais entre as categorias analisadas (10,76\%). Depois dessa, a dimensão de período (modelo 4) é a que melhor explica as transições (10,74\%) e, por fim, a idade tem o menor poder de explicação (modelo 9). A análise dos ajustes por meio dos critérios AIC e BIC, no geral, confirma esse resultado. A inclusão nos modelos de dois e três fatores aumenta marginalmente o poder de explicação dos modelos, e o modelo IPC deu conta de 10,8\% da variância da tabela de contingência (modelo 7).

TABELA 1

Ajuste do modelo incluindo idade (I), período (P), coorte (C), origem (O) e destino (D) Regiões Metropolitanas (1) - 2002/2015

\begin{tabular}{|c|c|c|c|c|c|c|}
\hline & Modelos & $\mathrm{G}^{2}$ & $\Delta \mathrm{G}^{2}$ & $\mathrm{R}^{2}(\%)$ & $\mathrm{AIC}$ & $\mathrm{BIC}$ \\
\hline 1 & Nulo & 142494 & & & 127102 & 127102 \\
\hline 2 & $O+D$ & 127229,6 & 15264,5 & 10,712 & 4,1538 & -678876 \\
\hline 3 & $P$ & 142425 & 69,1 & 0,048 & 4,3644 & -663748 \\
\hline 4 & $O+D+P$ & 127184,8 & 15309,2 & 10,744 & 4,1532 & -678876 \\
\hline 5 & $O+D+P+1$ & 127162,6 & 15331,5 & 10,759 & 4,1532 & -678775 \\
\hline 6 & $O+D+P+C$ & 127115,9 & 15378,2 & 10,792 & 4,1526 & -678800 \\
\hline 7 & $O+D+P+I+C$ & 127102,8 & 15391,3 & 10,801 & 4,1528 & -678690 \\
\hline 8 & I & 142146,1 & 348,0 & 0,244 & 4,3607 & -663949 \\
\hline 9 & $0+D+1$ & 127207 & 15287,0 & 10,728 & 4,1537 & -678776 \\
\hline 5 & $O+D+P+1$ & 127162,6 & 15331,5 & 10,759 & 4,1532 & -678775 \\
\hline 10 & $O+D+1+C$ & 127133,4 & 15360,7 & 10,780 & 4,1531 & -678704 \\
\hline 7 & $O+D+P+I+C$ & 127102,8 & 15391,3 & 10,801 & 4,1528 & -678690 \\
\hline 11 & $\mathrm{C}$ & 142220,9 & 273,2 & 0,192 & 4,3618 & -663851 \\
\hline 12 & $O+D+C$ & 127156,2 & 15337,9 & 10,764 & 4,1531 & -678804 \\
\hline 10 & $O+D+1+C$ & 127133,4 & 15360,7 & 10,780 & 4,1531 & -678704 \\
\hline 6 & $O+D+P+C$ & 127115,9 & 15378,2 & 10,792 & 4,1526 & -678800 \\
\hline 7 & $O+D+P+I+C$ & 127102,8 & 15391,3 & 10,801 & 4,1528 & -678690 \\
\hline
\end{tabular}

Fonte: IBGE. Pesquisa Mensal de Emprego, 2002-2015. Elaboração das autoras.

(1) Referem-se às RMs de Recife, Salvador, Belo Horizonte, Rio de Janeiro, São Paulo e Porto Alegre.

\footnotetext{
${ }^{5}$ A classificação sócio-ocupacional adotada é baseada em IBGE (1994), que considera o nível educacional, nível de rendimento e o cruzamento das variáveis ocupação, posição na ocupação, setor de atividade, contribuição para a previdência e carteira assinada.
} 
Aspectos representados pelas coortes de nascimento se mostraram, assim, fundamentais para o entendimento da dinâmica de transição entre as categorias ocupacionais formadas. Como a variável de educação não foi incluída até esse momento, parte desse resultado pode ter origem em diferenças tanto em "qualidade" quanto em “quantidade" do ensino que foi ofertado às diferentes gerações que se encontram no mercado de trabalho no período analisado (HERMETO, 2002). Além disso, destaca-se o papel importante de cada nova coorte de possibilitar a mudança advinda de novos valores, como, por exemplo, o questionamento entre as mulheres em relação aos sacrifícios em termos de condições de trabalho e prestígio da ocupação.

Período também se mostrou importante para modelar as frequências de transição. No modelo em questão, em que uma categoria passou por mudanças institucionais - a das trabalhadoras domésticas -, a relevância do marcador temporal abarca os níveis de crescimento econômico e as mudanças devidas aos novos encargos e modelos de trabalho. o Gráfico 1 apresenta a frequência de domésticas por ano na amostra, além do grupo de origem dessas.

GRÁFICO 1

Origem das mulheres no serviço doméstico ao longo do tempo Regiões Metropolitanas (1) - 2002-2015

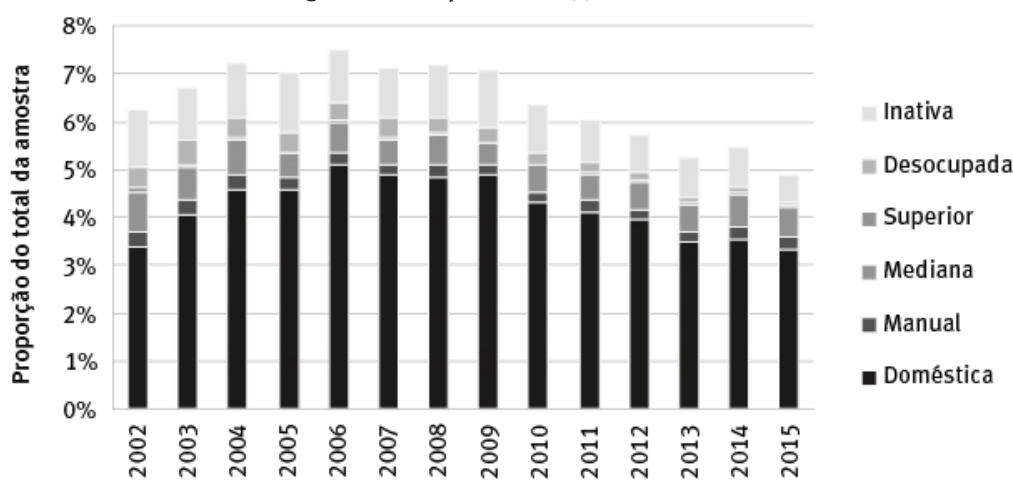

Fonte: IBGE. Pesquisa Mensal de Emprego, 2002-2015. Elaboração das autoras.

(1) Referem-se às RMs de Recife, Salvador, Belo Horizonte, Rio de Janeiro, São Paulo e Porto Alegre.

Os ciclos econômicos de crescimento e retração afetam a demanda por trabalho e os níveis de exigência dos empregadores (DEX; BUKODI, 2013), tendo efeitos também na decisão de ofertar ou não trabalho e no salário reserva. Percebe-se que há uma queda no número de trabalhadoras domésticas a partir de 2009, o que coincidiu com a crise econômica que atingiu o Brasil nesse ano, indicando um fenômeno com raízes na demanda. Entretanto, a recuperação da economia em 2010 não foi acompanhada pelo mesmo fenômeno nas taxas de trabalho doméstico, indicando uma insuficiência da oferta desse trabalho. A demanda pelo serviço prestado por essas mulheres é bem estável e variações no número de trabalhadoras domésticas ocorrem mais por fatores de oferta (PINHEIRO; FONTOURA; PEDROSA, 2011), principalmente entre as mulheres mais jovens (BALTAR; LEONE, 2015), 
do que pela estigmatização e baixos níveis de rendimento, pela preferência de entrarem no mercado de trabalho em outras ocupações, ou até mesmo de permanecerem desocupadas a trabalharem como domésticas.

Também considerada entre os efeitos de período, a Emenda Constitucional 72, conhecida como PEC das domésticas, é uma grande mudança institucional. Foi aprovada em 2013, mas as principais mudanças só entraram em vigor depois da aprovação da lei complementar, que regulamenta a medida em 2015. Essa lei reduziu a existência de exceções na concessão de direitos aos trabalhadores domésticos e, assim, aumentou o custo para o empregador ao mesmo tempo que contribuiu para o estabelecimento de padrões decentes de trabalho nessa ocupação. Depois de anunciada essa mudança, em 2013, houve uma queda no número de empregadas domésticas, principalmente as que permaneceram na ocupação. Entretanto, no último ano incluído no modelo (2014), a medida não tinha entrado plenamente em vigor, podendo ser avaliado somente o impacto da expectativa de mudanças causada pela emenda. Mais uma vez, como a demanda por esse trabalhador é consideravelmente elástica (PINHEIRO; FONTOURA; PEDROSA, 2011), a redução no número de trabalhadoras domésticas está mais relacionada ao movimento de retração que já estava em curso, originado mais por fatores geracionais do que pelo efeito dessa mudança.

A idade das mulheres capta os movimentos de entrada e saída do mercado de trabalho em função de aposentadoria, término dos estudos ou maternidade, mas também representa as movimentações entre ocupações que ocorreram por maior maturidade e acumulação de capital via experiência. Até mesmo a decisão do momento de realizar a transição para a inatividade varia com a categoria sócio-ocupacional da mulher, já que existem diferentes padrões de acúmulos de renda entre essas, assim como distintos salários reserva (REIS; GONZAGA, 2006).

No período analisado houve um deslocamento da distribuição etária das domésticas para a direita, evidência do envelhecimento dessa ocupação (Gráfico 2). A média de idade das domésticas passou de 38 para 42 anos, entre 2002 e 2014, ou seja, houve uma elevação na média de idade, assim como encontrado por Autor e Dorn (2009) nas ocupações que estão ficando obsoletas ou "ficando velhas". É importante ressaltar que houve um aumento da média de idade das mulheres em toda a amostra, mas esse avanço foi maior entre as domésticas, já que as mulheres da amostra tinham em média 38 anos, em 2002, e 39 anos, em 2014. Além da maior expectativa de vida e, assim, aposentadoria ${ }^{6}$ cada vez mais tarde, o aumento da média etária no emprego doméstico está relacionado à obtenção de habilidades específicas referentes à ocupação, elevando o sacrifício de mudar de ocupação de trabalhadores com muita experiência. Ao mesmo tempo, menos trabalhadores jovens vão ser atraídos para essa atividade, já que está se tornando uma ocupação menos atrativa ou obsoleta. Assim, como enunciado por Autor e Dorn (2009, p. 46), “occupations

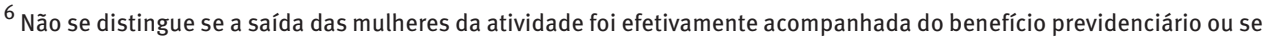
constitui apenas uma saída do mercado de trabalho.
} 
will 'get old' as their employment declines- that is, the mean age of an occupation's work force will rise”. Esse perfil etário diferenciado em um dos grupos sócio-ocupacionais formados faz com que a variável idade seja importante para a modelagem das frequências.

\section{GRÁFICO 2}

Composição etária da categoria das empregadas domésticas, segundo a condição de atividade na primeira observação

Regiões Metropolitanas (1) - 2002-2014

2002

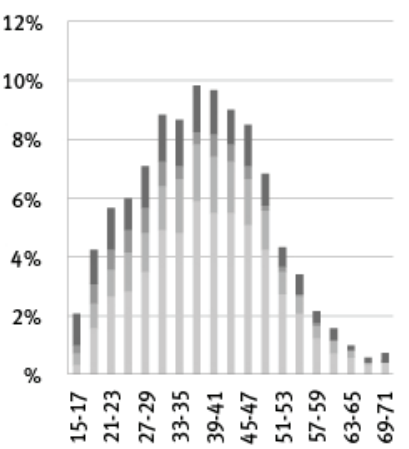

2008

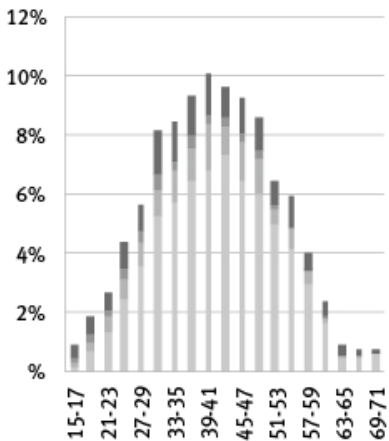

2014

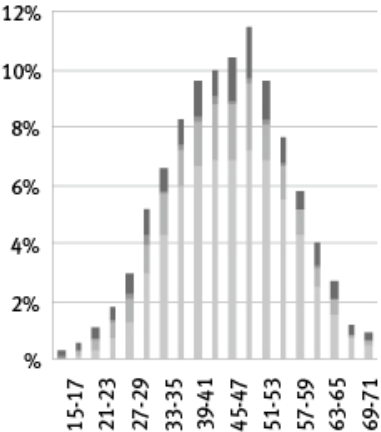

Inativas

Desocupadas Outras

Domésticas

Fonte: IBGE. Pesquisa Mensal de Emprego, 2002-2015. Elaboração das autoras

(1) Referem-se às RMs de Recife, Salvador, Belo Horizonte, Rio de Janeiro, São Paulo e Porto Alegre.

É importante ressaltar que existe uma interdependência entre esses efeitos. Por exemplo, a mudança na legislação não afetou as mulheres em diferentes fases do ciclo de vida da mesma forma, assim como a idade não tem o mesmo efeito em mulheres de gerações diferentes, criadas com diferentes valores. A interseccionalidade característica dessa ocupação é comprovada pela comparação de ajuste dos modelos, já que realmente o melhor ajuste é o do modelo incluindo todas as características, mesmo levando em conta a penalidade da redução dos graus de liberdade.

Além desses marcadores temporais, geracionais e de idade, outras características do indivíduo são importantes na determinação das transições ocupacionais. Considerando a existência da classificação de doméstica entre as categorias criadas, uma característica fundamental seria o gênero, entretanto, esse não precisa ser incluído, já que a amostra é composta apenas por mulheres. As estatísticas de ajuste dos modelos que incluem as demais variáveis (região metropolitana, cor/raça, condição na família, anos de estudo) são apresentadas na Tabela 2.

Individualmente, a condição na família é a variável desse grupo que explica maior parte da dispersão da tabela de contingência (14,96\%), seguida por cor/raça (14,65\%). As estatísticas AIC e BIC confirmam esse resultado. As decisões de entrada e saída do mercado de trabalho, além das transições entre ocupações, sofrem influência da composição das famílias, mais especificamente da posição que o indivíduo ocupa nessas. As domésticas 
constituem o grupo formado por maior proporção de mulheres como principais na família, apontando assim para o surgimento de uma grande instabilidade no domicílio quando essa profissional realiza a transição ocupacional, já que, sem o capital humano intrínseco àquele ofício, sua posição pode ser mais vulnerável do que na ocupação anterior (Gráfico 3). Ou seja, o padrão encontrado de composição familiar das domésticas, combinado à importância da condição na família para modelar as frequências das transições, sugere uma rigidez ocupacional maior para essa ocupação devido aos custos da mobilidade ocupacional.

TABELA 2

Ajuste do modelo incluindo região metropolitana (RM), raça/cor, grupo de anos de estudo (Educ) e condição na família (CF), além de idade, período e coorte

Regiões Metropolitanas (1) - 2002/2015

\begin{tabular}{|c|c|c|c|c|}
\hline Modelo & $\Delta \mathrm{G}^{2}$ & $\mathrm{R}^{2}(\%)$ & AIC & BIC \\
\hline Nulo & & & 4,3652 & 127102 \\
\hline $\mathrm{O}+\mathrm{D}$ & 15264,5 & 10,712 & 4,1538 & -678876 \\
\hline$O+D+R M$ & 17577,9 & 12,34 & 4,1218 & -681134 \\
\hline $\mathrm{O}+\mathrm{D}+\mathrm{Cor}$ & 20879,3 & 14,65 & 4,0759 & -684469 \\
\hline $\mathrm{O}+\mathrm{D}+\mathrm{CF}$ & 21310,3 & 14,96 & 4,0700 & -684888 \\
\hline$O+D+$ Educ & 17606,9 & 12,36 & 4,1214 & -681174 \\
\hline $\mathrm{O}+\mathrm{D}+\mathrm{RM}+\mathrm{CF}$ & 23331,4 & 16,37 & 4,0421 & -686854 \\
\hline $\mathrm{O}+\mathrm{D}+\mathrm{Cor}+\mathrm{CF}$ & 26869,1 & 18,86 & 3,9929 & -690425 \\
\hline $\mathrm{O}+\mathrm{D}+\mathrm{RM}+\mathrm{Cor}$ & 22284,2 & 15,64 & 4,0566 & -685818 \\
\hline $\mathrm{O}+\mathrm{D}+\mathrm{RM}+\mathrm{Educ}$ & 20090,7 & 14,10 & 4,0871 & -683602 \\
\hline $\mathrm{O}+\mathrm{D}+\mathrm{Educ}+\mathrm{CF}$ & 24062,9 & 16,89 & 4,0319 & -687595 \\
\hline $\mathrm{O}+\mathrm{D}+\mathrm{Cor}+\mathrm{Educ}$ & 23207,0 & 16,29 & 4,0438 & -686752 \\
\hline $\mathrm{O}+\mathrm{D}+\mathrm{RM}+\mathrm{Cor}+\mathrm{Educ}+\mathrm{CF}$ & 30907,2 & 21,69 & 3,937 & -694362 \\
\hline $\mathrm{O}+\mathrm{D}+\mathrm{I}+\mathrm{RM}+\mathrm{CF}+\mathrm{Cor}+\mathrm{EduC}$ & 30935,4 & 21,71 & 3,9370 & -694267 \\
\hline $\mathrm{O}+\mathrm{D}+\mathrm{P}+\mathrm{RM}+\mathrm{CF}+\mathrm{Cor}+\mathrm{EduC}$ & 30984,0 & 21,74 & 3,9362 & -694394 \\
\hline $\mathrm{O}+\mathrm{D}+\mathrm{C}+\mathrm{RM}+\mathrm{CF}+\mathrm{Cor}+\mathrm{Educ}$ & 30978,3 & 21,74 & 3,9365 & -694288 \\
\hline $\mathrm{O}+\mathrm{D}+\mathrm{P}+\mathrm{C}+\mathrm{RM}+\mathrm{CF}+\mathrm{Cor}+\mathrm{EduC}$ & 31039,7 & 21,78 & 3,9357 & -694305 \\
\hline $\mathrm{O}+\mathrm{D}+\mathrm{I}+\mathrm{C}+\mathrm{RM}+\mathrm{CF}+\mathrm{Cor}+\mathrm{Educ}$ & 31039,0 & 21,78 & 3,9359 & -694226 \\
\hline $\mathrm{O}+\mathrm{D}+\mathrm{I}+\mathrm{P}+\mathrm{RM}+\mathrm{CF}+\mathrm{Cor}+\mathrm{Educ}$ & 31010,5 & 21,76 & 3,9361 & -694298 \\
\hline $\mathrm{O}+\mathrm{D}+\mathrm{I}+\mathrm{P}+\mathrm{C}+\mathrm{RM}+\mathrm{CF}+\mathrm{Cor}+\mathrm{EduC}$ & 31072,5 & 21,81 & 3,9356 & -694214 \\
\hline
\end{tabular}

Fonte: IBGE. Pesquisa Mensal de Emprego, 2002-2015. Elaboração das autoras.

(1) Referem-se às RMs de Recife, Salvador, Belo Horizonte, Rio de Janeiro, São Paulo e Porto Alegre.

Além de diferenças nas taxas de participação, e na direção dos resultados de Pinheiro, Fontoura e Pedrosa (2011), há um envelhecimento da ocupação distinto para os grupos de domésticas de cores/raças diferentes. Pode-se perceber no Gráfico 4 que, nos períodos inicial e final da análise, há envelhecimento nos dois grupos, mas em ambos os anos as curvas de mulheres brancas estão mais à direita do que as das negras. Ou seja, apesar de essa mudança ser uma realidade no geral, ela é mais predominante entre as trabalhadoras brancas. 


\section{GRÁFICO 3}

Composição etária das trabalhadoras domésticas e mulheres nas demais ocupações, segundo posição na família

Regiões Metropolitanas (1) - 2002/2015

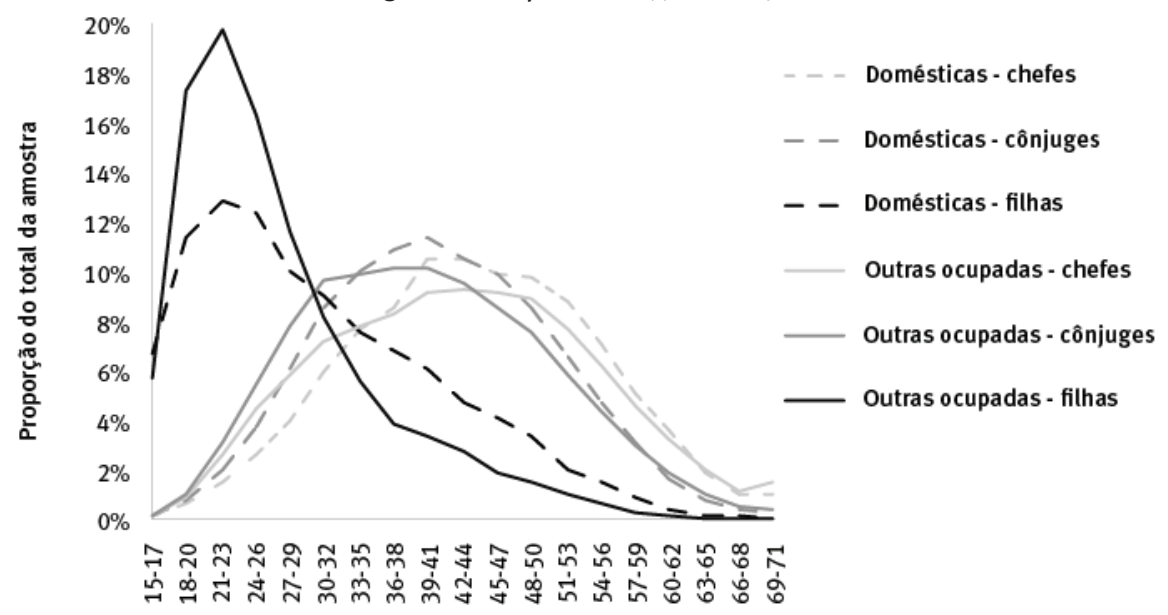

Fonte: IBGE. Pesquisa Mensal de Emprego, 2002-2015. Elaboração das autoras.

(1) Referem-se às RMs de Recife, Salvador, Belo Horizonte, Rio de Janeiro, São Paulo e Porto Alegre.

\section{GRÁFICO 4}

Distribuição etária das trabalhadoras domésticas, por cor/raça Regiões Metropolitanas (1) - 2002-2014

2002

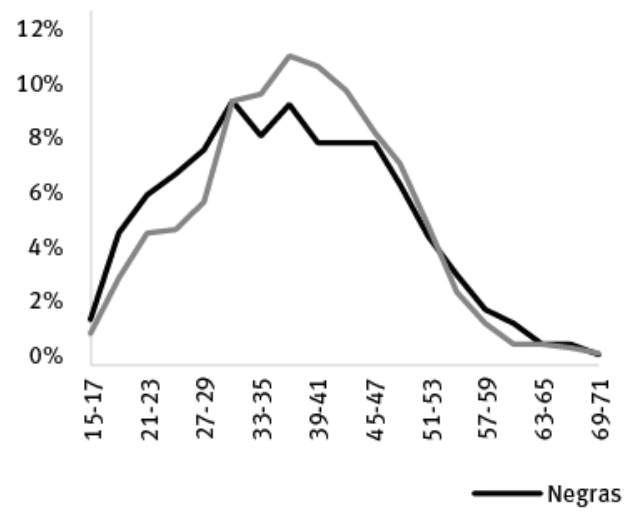

2014

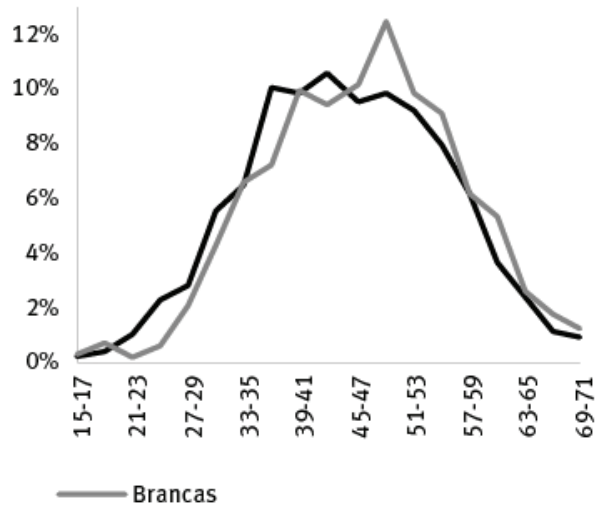

Fonte: IBGE. Pesquisa Mensal de Emprego, 2002-2015. Elaboração das autoras.

(1) Referem-se às RMs de Recife, Salvador, Belo Horizonte, Rio de Janeiro, São Paulo e Porto Alegre.

Com menor poder preditivo das frequências de alocação e transição entre as categorias, não são encontradas diferenças determinantes nos padrões transacionais específicos das regiões metropolitanas incluídas na análise, assim como dos diferentes grupos educacionais. A baixa influência de fatores locacionais específicos de cada região pode ser justificada pela restrição do universo analisado apenas às áreas urbanas das regiões metropolitanas. Assim, restringiu-se a diversidade das condições de influência do espaço 
nas decisões ocupacionais. Em relação à escolaridade, é importante ressaltar que se incluem no modelo tanto a ocupação destino quanto a origem, que já captam grande parte do efeito da escolaridade na alocação na ocupação inicial, restando baixo poder de explicação para a variável escolaridade nas transições. Ou seja, o efeito incremental nas transições da educação da mulher é baixo.

Analisando as variáveis adicionais combinadas duas a duas, aquelas que são destaque individualmente também representam a maior parte da dispersão combinada, apontando que não há redundância de informações entre essas características; cor/raça e condição na família são responsáveis, juntas, por $18,86 \%$. Nos modelos com variáveis adicionais incluindo idade, período e coorte, a condição na família é ainda a principal variável adicional, seguida por raça/cor. Porém, há uma mudança na ordem de poder de explicação das frequências, pois, apesar de a idade ainda ser a variável menos explicativa, agora o modelo de período é o melhor e não mais o de coorte. Isso indica que algumas características que estavam sendo captadas pela variável que representa as gerações agora estão explicitadas pelas demais variáveis que foram acrescentadas.

A hipótese inicial é de que os efeitos de coorte sejam redundantes com os efeitos captados pela escolaridade, uma vez que a diferença na qualidade recebida ao longo das gerações de indivíduos e a fração da população em cada grupo educacional são efeitos de coorte (HERMETO, 2002). Entretanto, não é isso que se encontra ao se compararem ajustes dos modelos, sendo que as mudanças que a educação sofreu ao longo das coortes não chegaram a influenciar de maneira contundente as empregadas domésticas. As variáveis responsáveis por essa mudança são raça e condição no domicílio. Ou seja, ocorreram mudanças no impacto de ser uma mulher negra e de estar em determinada posição no domicílio na alocação entre cada grupo de ocupações ao longo das gerações consideradas, já que parte do efeito de coorte na mobilidade e inserção ocupacional está captada pela variável cor/raça. Em relação à posição na estrutura familiar, pode-se concluir que houve mudanças nos papéis da mulher que influenciam sua inserção no mercado de trabalho ao longo das coortes, assim como na influência que a cor/raça possui na inserção e mobilidade ocupacionais das mulheres. Há uma influência em ser cônjuge, filha ou chefe de família, bem como em ser branca ou negra, na decisão de ofertar ou não trabalho e ainda na ocupação escolhida e nas transições ocupacionais realizadas; mas esse efeito está mudando ao longo das coortes de nascimento.

\section{Modelos topológicos}

Até aqui, as variáveis incluídas ajudaram a explicar todas as transições realizadas pelas mulheres. Os próximos modelos incluem um desenho topológico que diferencia as caselas da matriz de transição, permitindo que se inicie a análise específica dos movimentos das mulheres. Testando as hipóteses descritas na metodologia por meio dos modelos topológicos, percebe-se que o modelo que diferencia a imobilidade da mobilidade se mostrou 
melhor do que o modelo padrão. Além disso, o modelo que diferencia a mobilidade ascendente da descendente não apresentou melhor ajuste em relação ao modelo mobilidade/imobilidade, ou seja, não existem indícios de um padrão que separe a mobilidade ascendente da descendente, ou essa ordenação que foi assumida (ocupadas superior, intermediária, manual, doméstica, desempregada e inativa) não é a verdadeira. Esse resultado pode ser justificado pela ausência de sentido teórico em enquadrar as inativas e desocupadas na base da hierarquia entre ocupações, uma vez que essas mulheres formam um grupo com características específicas.

A diferenciação das transições pela "distância" percorrida foi confirmada pela comparação de ajustes dos modelos, assumindo a ordem descrita e considerando que distâncias iguais se comportam da mesma forma, seja numa mudança para cima na hierarquia, seja para baixo (transições com distâncias de uma unidade são movimentos para classes vizinhas, como, por exemplo, uma transição de uma ocupação manual para uma intermediária). Assim, pode-se concluir que a hierarquia proposta entre as classes ocupacionais representa as encontradas na realidade.

Vários formatos de separação das transições realizadas envolvendo inatividade e desemprego foram testados e decidiu-se considerar em conjunto as mulheres desses grupos. 0 modelo escolhido, que inclui todas as hipóteses não rejeitadas no seu desenho, é apresentado no Quadro 2. Cada grupo de ocupação se comporta de maneira única nas transições para desocupação e inatividade, e da mesma maneira originando-se ou destinando-se para essas situações (padrões 4, 5, 6 e 7 no Quadro 2). Diferenciar os movimentos da inatividade para a desocupação e o movimento contrário não comprovou a existência de desemprego que está oculto pelo desalento (padrão 1). Por fim, encontra-se que a imobilidade é diferente entre os grupos ocupacionais e condições de atividade (padrões 8 a 13).

QUADRO 2

Desenho topológico escolhido

Regiões Metropolitanas (1) - 2002/2015

\begin{tabular}{|l|cccccc|}
\hline \multirow{2}{*}{ Origem } & \multicolumn{7}{c|}{ Destino } \\
\multicolumn{1}{|c}{ Superior } & Mediana & Manual & Doméstica & Desocupada & Inativa \\
\hline Superior & 8 & 1 & 2 & 3 & 7 & 7 \\
Mediana & 1 & 9 & 1 & 2 & 6 & 6 \\
Manual & 2 & 1 & 10 & 1 & 5 & 5 \\
Doméstica & 3 & 2 & 1 & 11 & 4 & 4 \\
Desocupada & 7 & 6 & 5 & 4 & 12 & 1 \\
Inativa & 7 & 6 & 5 & 4 & 1 & 13 \\
\hline
\end{tabular}

Fonte: Elaboração das autoras.

(1) Referem-se às RMs de Recife, Salvador, Belo Horizonte, Rio de Janeiro, São Paulo e Porto Alegre.

A escolha desse modelo reforça a classificação ocupacional adotada, assim como a segregação entre ocupações superiores, intermediárias e manuais, e entre essas e o emprego doméstico (padrões 1, 2 e 3). A entrada e saída para desocupação e inatividade é mais bem modelada quando se considera cada uma dessas classes ocupacionais 
individualmente, apontando para uma diferenciação também na decisão de ofertar o emprego e na facilidade de obtê-lo quando é decidido realizar essa oferta (padrões 4, 5, 6 e 7). Além disso, as transições do emprego doméstico para o emprego manual não apresentam o mesmo comportamento do que do doméstico para o mediano e o superior (já incluídas as características individuais e as que controlam para ciclo de vida, conjuntura e geração). É importante destacar que o modelo escolhido apresenta melhor ajuste ainda em relação ao modelo saturado na origem e destino.

Os coeficientes do modelo topológico são apresentados na Tabela 3. Os coeficientes da imobilidade das ocupações manuais, intermediárias, domésticas e desocupadas são menores do que a unidade, podendo-se falar em "déficits" na frequência dessas imobilidades em comparação à referência, que é a mobilidade com uma casela de distância. Dentre esses, a maior diferença na frequência é da desocupação, o que se justifica por ser uma situação inerentemente transitória, seguida pelas domésticas. Com diferença de $41 \%$ em relação à mobilidade para uma posição vizinha, o emprego doméstico apresenta maior mobilidade entre as categorias ocupacionais criadas. Entretanto, a análise descritiva dos dados mostrou padrão forte de imobilidade (em dois anos essa foi a ocupação com menos transições, em dois anos a segunda categoria e nunca ocupou a posição de menor imobilidade), apresentando indícios da existência da "armadilha da ocupação" (SAITO; SOUZA, 2008). Esses resultados aparentemente contraditórios podem ser justificados pela capacidade do modelo em eliminar o efeito de outras características, que eram de fato as responsáveis pela aparente mobilidade da ocupação.

TABELA 3

Coeficientes estimados para o modelo escolhido Regiões Metropolitanas (1) - 2002/2015

\begin{tabular}{lccc}
\hline & Coeficientes & Erros-padrão & P >z \\
\hline 1 Diagonal 2 & - & - & - \\
2 Diagonal 3 & $-0,153$ & 0,022 & 0,000 \\
3 Diagonal 4 & $-0,150$ & 0,088 & 0,086 \\
7 Ocupada sup. - inatividade / desemprego & $-0,219$ & 0,025 & 0,000 \\
6 Ocupada med. - inatividade / desemprego & $-0,130$ & 0,018 & 0,000 \\
5 Ocupada man. - inatividade / desemprego & 0,062 & 0,019 & 0,001 \\
4 Doméstica - inatividade / desemprego & $-0,042$ & 0,030 & 0,166 \\
8 Imobilidade superior & 1,025 & 0,033 & 0,000 \\
9 Imobilidade intermediária & 0,798 & 0,027 & 0,000 \\
10 Imobilidade manual & 0,820 & 0,028 & 0,000 \\
11 Imobilidade doméstica & 0,589 & 0,052 & 0,000 \\
12 Imobilidade desemprego & 0,074 & 0,032 & 0,022 \\
13 Imobilidade inativa & 1,195 & 0,021 & 0,000 \\
\hline
\end{tabular}

Fonte: IBGE. Pesquisa Mensal de Emprego, 2002-2015. Elaboração das autoras.

(1) Referem-se às RMs de Recife, Salvador, Belo Horizonte, Rio de Janeiro, São Paulo e Porto Alegre. 
Assim, há um viés de mobilidade no emprego doméstico, contrabalanceado pelo perfil das trabalhadoras, o que vai ao encontro da desproteção dessa profissional, promovida pela desvalorização e desregulação, que desincentivam a continuidade nesta ocupação. Ou seja, além de não atrair mulheres trabalhando em outras ocupações ou fora do mercado de trabalho, essa ocupação também funciona como uma "alavanca" para outras profissões, já que quando têm outra oportunidade as mulheres preferem deixar esse trabalho.

\section{Probabilidades preditas}

Por fim, são analisadas as probabilidades preditas de origem e destino condicionais, segundo algumas características selecionadas, obtidas mantendo as demais características fixas nas médias. A partir de 2008 há uma redução na probabilidade de inserção no emprego doméstico dos três grupos mais jovens incluídos no modelo, ao mesmo tempo que se eleva a probabilidade de inserção das mais idosas, desenhando assim um quadro de envelhecimento nessa ocupação. A maior presença de trabalhadoras mais velhas nessa profissão vai ao encontro da expansão do período de atividade profissional durante o ciclo de vida das mulheres, já que as mulheres demoram cada vez mais para realizar a transição para a inatividade.

\section{GRÁFICO 5}

Probabilidade de estar ocupada como empregada doméstica, por grupos etários, controlando pelas demais características individuais

Regiões Metropolitanas (1) - 2002-2014

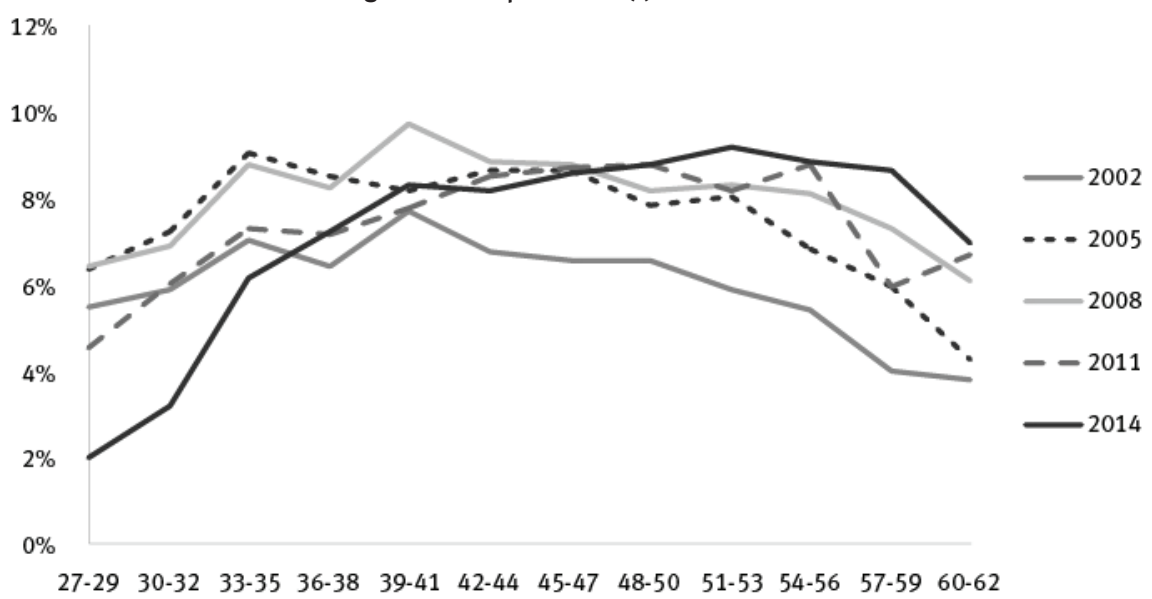

Fonte: IBGE. Pesquisa Mensal de Emprego, 2002-2015. Elaboração das autoras

(1) Referem-se às RMs de Recife, Salvador, Belo Horizonte, Rio de Janeiro, São Paulo e Porto Alegre.

A probabilidade de estar empregada nas demais ocupações também apresentou uma tendência de crescimento entre 2002 e 2014 : de $9,4 \%$ para $11,1 \%$ nas manuais; de $21,8 \%$ para $23,4 \%$ nas intermediárias; e de $9,7 \%$ para $11,9 \%$ nas superiores. Esse crescimento não foi tão expressivo como no caso das domésticas, em que a chance quase dobrou nesse 
mesmo período (de 3,9\% para 7,8\%). A grande mudança que contrabalanceou a maior ocupação de mulheres idosas ao longo do tempo foi a menor saída para a inatividade, já que, em 2002, considerando todas as demais características, a probabilidade predita de estar inativa se a mulher tinha mais de 54 anos de idade era $54 \%$ e, em 2014, esse valor correspondia a 45\%. Ou seja, a maior participação das mulheres mais velhas nessa ocupação se dá pela saída mais tardia para a aposentadoria, fenômeno mais contundente nessa ocupação do que nos demais grupos ocupacionais construídos.

As probabilidades preditas e sua capacidade de isolar os efeitos das características incluídas podem ser utilizadas também para análises de raça nesse mercado de trabalho. Considerando o destino das mulheres que eram domésticas na primeira ocupação, brancas têm maior probabilidade de realizar a transição para todas as categorias de ocupações, e ainda para a inatividade, enquanto as negras têm 5 pontos percentuais a mais $(70,7 \%$ para brancas e $75,7 \%$ para negras) de probabilidade de permanecerem na ocupação de doméstica. As trabalhadoras domésticas negras têm maior probabilidade também de ficarem desempregadas. Deve-se ressaltar que essa probabilidade já é condicional na origem e as mulheres negras, além de terem maior probabilidade de serem domésticas, também têm maior chance de continuarem nessa ocupação.

No Gráfico 6 estão as diferenças nas probabilidades de negras e brancas estarem em determinada situação ou categoria ocupacional ao longo do período analisado. A chance de as mulheres brancas ocuparem ocupações superiores é maior do que a das negras, mesmo já considerando as demais diferenças como escolaridade e posição na família. A maior diferença entre os grupos está nas ocupações superiores, chegando a até 6 pontos percentuais a favor das mulheres brancas. Essa diferença, entretanto, foi se reduzindo ao longo do tempo. A segunda maior diferença, agora com as negras apresentando maior probabilidade, é na inatividade, ou seja, enquanto as brancas têm mais probabilidade de estarem em uma ocupação superior e gerencial, as negras têm mais probabilidade de estarem inativas. Além da ocupação superior, as mulheres brancas apresentam maior probabilidade de estarem em ocupações manuais, e ainda desempregadas. As negras, além da inatividade, possuem maior probabilidade de estarem em ocupações intermediárias e no serviço doméstico.

Pode-se observar que as diferenças, no geral, diminuíram ao longo dos anos analisados, seja nos grupos que "favorecem" as negras, seja naqueles que "desfavorecem" as negras. Esse resultado poderia sugerir uma equalização das diferenças raciais e superação de conflitos. Em relação ao emprego doméstico, entretanto, essa diferença está se mantendo em patamares constantes, indicando que a superação de estigmas e marcas ainda não é identificada, seja pela invisibilidade dessas trabalhadoras, seja pelo não reconhecimento desse serviço como trabalho, ou mesmo pelo peso adicional que possui esse trabalho essencialmente feminino e com heranças da servidão. 
GRÁFICO 6

Evolução temporal das diferenças entre brancas e negras nas probabilidades preditas de inserção em cada categoria ocupacional

Regiões Metropolitanas (1) - 2002-2014

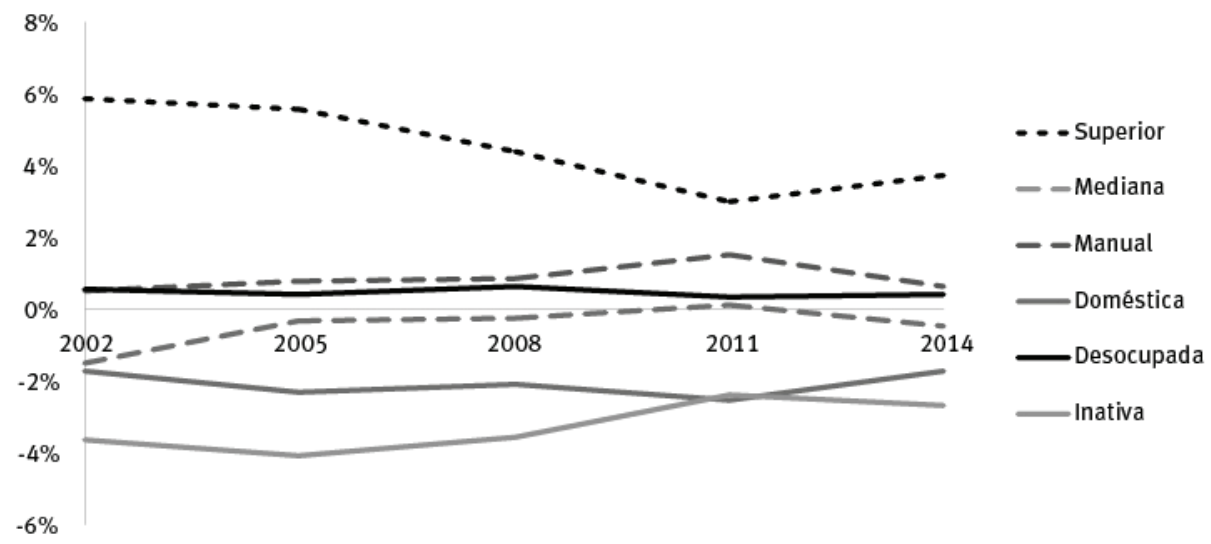

Fonte: IBGE. Pesquisa Mensal de Emprego, 2002-2015. Elaboração das autoras.

(1) Referem-se às RMs de Recife, Salvador, Belo Horizonte, Rio de Janeiro, São Paulo e Porto Alegre.

Nota: Em tons de preto estão as categorias em que as mulheres brancas têm maior probabilidade de estarem em relação às negras e em tons de cinza estão as categorias em que as negras têm mais chances de ocupar.

\section{Conclusão}

Esse estudo teve como objetivo investigar a existência de padrões específicos de inserção e mobilidade no trabalho doméstico. Esse mercado de trabalho está ficando menor e a ocupação está "ficando velha”, segundo a distribuição etária das domésticas. Duas mudanças no padrão de inserção nessa ocupação justificam e reforçam esse envelhecimento: as mulheres jovens estão entrando menos nessa ocupação; e as mulheres mais velhas estão demorando cada vez mais para realizar a transição para a inatividade. Esse movimento, entretanto, é mais intenso para mulheres brancas do que negras, apontando para uma manutenção do viés racial que a ocupação possui no Brasil.

A transição entre as coortes de nascimento com novas ideias e valores e vivenciando outras realidades se mostrou importante para explicar os movimentos de transição ocupacional. Além de efeitos puros de coorte, as mudanças geracionais se transpõem também para outras dimensões, principalmente condição na família e cor/raça. Encontra-se um efeito substancial em ser cônjuge, filha ou chefe de família na decisão de entrar no mercado de trabalho e na ocupação a ser exercida, observando-se que esse foi diferente ao longo das coortes de nascimento. Ou seja, ao longo de novas coortes de nascimento, a influência da posição na família na escolha ocupacional foi sendo alterada. É importante ressaltar que o emprego doméstico, dentre os grupos ocupacionais criados, é aquele com maior parcela de mulheres chefes de domicílio, reforçando a importância de se manterem ocupadas mesmo enfrentando situações de desproteção e discriminação. Da mesma forma, os resultados dos modelos mostram que a influência de ser negra, já controlada 
todas as demais características da mulher, na inserção e mobilidade entre as categorias de atividade é grande e distinta ao longo das coortes. Esse efeito está diminuindo, já que a diferença entre as probabilidades preditas (encontradas utilizando o melhor modelo para determinar as influências líquidas) de ocupação em cada categoria reduziu-se ao longo do período estudado.

A maior diferença nas probabilidades de inserção encontrada foi a de trabalhar em ocupações superiores, com probabilidades favoráveis às mulheres brancas. Favorável às mulheres negras, a segunda maior diferença, seguida da inatividade, está na probabilidade de estar ocupada como doméstica. Ou seja, inclusive depois de já se considerarem as diferenças de oportunidades educacionais entre brancas e negras, essas últimas têm mais chances de estarem inativas ou trabalharem como domésticas, enquanto as primeiras têm maior probabilidade de trabalharem em ocupações superiores. As diferenças nas probabilidades, entretanto, foram menores a cada ano analisado, apontando que se está evoluindo no combate à discriminação e segregação racial ocupacional. A maior probabilidade de as negras estarem no emprego doméstico, entretanto, se manteve em patamares constantes e, nessa ocupação, a superação desses estigmas e marcas nas quais se baseiam a discriminação ainda não está ocorrendo. Esse resultado vai ao encontro do menor envelhecimento da categoria de empregadas domésticas negras, indicando que para esse grupo a ocupação está "diminuindo" mais lentamente. Assim, até mesmo as melhorias sociais de redução da segregação ocupacional são menores para esse grupo de profissionais, somando à invisibilidade dessas trabalhadoras o peso adicional que possui esse trabalho essencialmente feminino e com heranças da servidão.

Por fim, altas taxas de mobilidade dessa atividade para as demais ocupações não são encontradas quando se analisam descritivamente os dados, mas são vistas nos resultados do modelo topológico multivariado. Isso ocorre porque a análise descritiva realizada é unidimensional e não isola o efeito das demais características dos indivíduos nessa ocupação. Assim, há uma tendência de mobilidade no emprego doméstico, seja para outras ocupações, seja para inatividade ou desemprego, mas que é ocultada pelo perfil das trabalhadoras dessa ocupação. Essa grande mobilidade intrínseca ao serviço doméstico remunerado vai ao encontro da desvalorização dessa profissional, promovida pela desproteção e desregulação, que desincentiva a continuação nessa ocupação.

\section{Referências}

AUTOR, D. H.; DORN, D. This job is getting old: measuring changes in job opportunities using occupational age structure. American Economic Review: Papers \& Proceedings, v. 99, n. 2, p. 45-51, 2009.

BALTAR, P.; LEONE, E. Perspectivas para o mercado de trabalho após o crescimento com inclusão social. Estudos Avançados, v. 29, n. 85, p. 53-67, 2015.

BYELOVA, K. Social and legal empowerment of domestic workers in Brazil. Tese (Mestrado) Norwegian University of Life Sciences, Noruega, 2014. 
DIEESE - Departamento Intersindical de Estatística e Estudos Econômicos. 0 emprego doméstico no Brasil. Estudos e Pesquisa, n. 68, 2013.

DEX, S.; BUKODI, E. Gender differences in job and occupational mobility in varying labour market conditions. Oxford: University of Oxford, 2013 (Barnett Working Paper, n. 13-03).

DUFFY, M. Doing the dirty work: gender, race, and reproductive labor in historical perspective. Gender \& Society, v. 21, n. 3, p. 313-336, 2007.

FEATHERMAN, D. L.; HAUSER, R. M. Prestige or socioeconomic scales in the study of occupational achievement? In: GRUSKY, D. B. (org.). Social stratification - class, race, and gender in sociological perspective. Madison: Institute for Research on Poverty, 1976. p. 403-422.

GUERRA, M. F. L. Trabalhadoras domésticas no Brasil: coortes, formas de contratação e famílias contratantes. Tese (Doutorado) - Universidade Federal de Minas Gerais, Belo Horizonte, 2017.

HERMETO, A. M. Acumulando informações e estudando mudanças ao longo do tempo: análises longitudinais do mercado de trabalho brasileiro. Tese (Doutorado) - Universidade Federal de Minas Gerais, Belo Horizonte, 2002.

IBGE - Instituto Brasileiro de Geografia e Estatística. Mapa do mercado de trabalho no Brasil. Rio de Janeiro, 1994.

KERGOAT, D. Divisão sexual do trabalho e relações sociais de sexo. In: TEIXEIRA, M.; EMÍLIO, M.; NOBRE, M. (org.). Trabalho e cidadania ativa para as mulheres: desafios para as políticas públicas. São Paulo: Coordenadoria Especial da Mulher, 2003. p. 55-64.

MANESCHY, M. C. O emprego doméstico e as relações de gênero no mundo do trabalho. Gênero na Amazônia, n. 3, p. 207-218, 2013.

OLIVEIRA, S. M.; COSTA, P. L. Condicionantes para a profissionalização do trabalho doméstico no Brasil: um olhar sobre a profissão em duas regiões metropolitanas - São Paulo e Salvador - na última década. In: ENCONTRO ANUAL DA ANPOCS, 36. Anais [...]. Águas de Lindóia: Anpocs, 2012.

PHANG, H. S. Labor market transitions of young women over the early life course: a multistate life table analysis. University of Wisconsin, Institute for Research on Poverty, 1995 (Institute for Research on Poverty Discussion Paper, n. 1062-95).

PINHEIRO, L.; FONTOURA, N.; PEDROSA, C. Situação atual das trabalhadoras domésticas no país. In: MORI, N. et al. (org.). Tensões e experiências: um retrato das trabalhadoras domésticas de Brasília e Salvador. Brasília: Centro de Estudos Feministas e Assessoria, 2011. p. 33-69.

POWERS, D.; XIE, Y. Statistical methods for categorical data analysis. 2. ed. Emerald, 2008.

REIS, M. C.; GONZAGA, G. Desemprego e qualificação: uma análise dos efeitos de idade, período e coorte. Pesquisa e Planejamento Econômico, v. 36, p. 367-412, 2006.

RIBAS, R. P.; SOARES, S. S. D. Sobre o painel da pesquisa mensal de emprego (PME) do IBGE. Brasília: Ipea, novembro de 2008. (Texto para Discussão, n. 1348).

RYDER, N. B. The cohort as a concept in the study of social change. American Sociological Review, v. 30, p. 843-861, 1965.

SAITO, K.; SOUZA, A. P. A mobilidade ocupacional das trabalhadoras domésticas no Brasil. In: ENCONTRO NACIONAL DE ECONOMIA, 36. Anais [...]. Salvador: Anpec, 2008.

TREIMAN, D. J. Occupational prestige in comparative perspective. 1976. In: GRUSKY, D. B. (org.). Social stratification - class, race, and gender in sociological perspective. 3. ed. Colorado: Westview Press, 2008. 
YANG, Y.; FU, W. J.; LAND, K. C. A methodological comparison of age-period-cohort models: intrinsic estimator and conventional generalized linear models. Sociological Methodology, n. 34, p.75-110, 2004.

\title{
Sobre as autoras
}

Larissa Giardini Simões é doutoranda em Economia pelo Centro de Desenvolvimento e Planejamento Regional (Cedeplar), da Universidade Federal de Minas Gerais (UFMG).

Ana Maria Hermeto é doutora em Demografia pelo Centro de Desenvolvimento e Planejamento Regional (Cedeplar), da Universidade Federal de Minas Gerais (UFMG). Professora associada do Cedeplar/UFMG.

\section{Endereço para correspondência}

\author{
Larissa Giardini Simões \\ Cedeplar/Face/UFMG \\ Av. Antonio Carlos, 6627, Pampulha \\ 31270-901 - Belo Horizonte-MG, Brasil \\ Ana Maria Hermeto \\ Cedeplar/Face/UFMG \\ Av. Antonio Carlos, 6627, Pampulha \\ 31270-901 - Belo Horizonte-MG, Brasil
}

\begin{abstract}
Recent patterns of occupational placement and mobility of paid domestic work in metropolitan Brazil: discontinuity and persistence
\end{abstract}

Essentially female, black/brown and poor, the occupation of domestic worker is treated differently even by the labor legislation. This paper aims to identify how the women's life cycle, generations, and other individual characteristics, as well as the macroeconomic situation and institutional changes, affect their chances of being and remaining a domestic worker in the metropolitan areas of Brazil in recent years. Data from Monthly Employment Research, from 2002 to 2015, was applied in an age-period-cohort log-linear modeling of the transition and immobility frequencies from employment categories. The conjuncture aspect is the most influential, followed by cohort. This occupation is both shrinking and "getting older" as fewer young women are participating in this labor market while older women take up more space. This is related both to the postponement of retirement and the lowest occupational mobility at a later stage in life. Furthermore, being black/brown is largely influential on insertion and occupational mobility that is shifting across birth cohorts and decreasing overtime, even though the difference in probability for black/brown and white women being domestic workers remains constant. Moreover, domestic work is more unstable than other occupations, contradicting the previous notion of an occupational trap that was in fact due to individual characteristics of workers.

Keywords: Paid domestic work. Occupational mobility. Aging. Life cycle. 


\section{Resumen}

Patrones recientes de inserción y movilidad en el trabajo doméstico remunerado en el área metropolitana de Brasil: discontinuidad y persistencia

Esencialmente femenino, negro y pobre, el empleo doméstico es tratado de manera distinta incluso por la legislación. Este estudio tiene como objetivo identificar cómo el ciclo de vida de las mujeres, la generación y otras características individuales, así como factores coyunturales, afectan la posibilidad de estar y quedarse en un empleo doméstico remunerado en el área metropolitana de Brasil en los últimos años. Los datos de la Encuesta Mensual de Empleo de 2002 a 2015 son aplicados en modelo log-linear de edad-período-cohorte de frecuencias de transición e inmovilidad de las categorías de empleo. La coyuntura tiene el mayor efecto, seguida de la cohorte. Esta ocupación se está reduciendo y «envejeciendo» a medida que menos mujeres jóvenes participan en este mercado laboral, mientras que las mujeres mayores ocupan cada vez más espacio, combinando el aplazamiento de la jubilación con una menor movilidad laboral en una etapa más avanzada de la vida. Además, hay un gran efecto de ser negra en la inserción y la movilidad ocupacional que está cambiando a lo largo de las cohortes de nacimiento. Sin embargo, la diferencia en la probabilidad entre mujeres blancas y negras que trabajan como empleadas domésticas permanece constante. Además, el empleo doméstico tiene mayor movilidad que los demás, lo que contradice la noción anterior de una trampa de ocupación, ya que la aparente movilidad se debe a las características individuales de los trabajadores.

Palabras clave: Empleo doméstico. Movilidad ocupacional. Envejecimiento. Ciclo vital.

Recebido para publicação em 19/09/2019 Aceito para publicação em 22/10/2019 